\title{
ARE CAPITAL INFLOWS EXPANSIONARY OR CONTRACTIONARY? THEORY, POLICY IMPLICATIONS, AND SOME EVIDENCE
}

\author{
Olivier Blanchard \\ Jonathan D. Ostry \\ Atish R. Ghosh \\ Marcos Chamon \\ Working Paper 21619 \\ http://www.nber.org/papers/w21619 \\ NATIONAL BUREAU OF ECONOMIC RESEARCH \\ 1050 Massachusetts Avenue \\ Cambridge, MA 02138 \\ October 2015
}

We are grateful to Maurice Obstfeld, Mahvash Qureshi, and seminar participants at The Role of Central Banks in Modern Times: Twenty-Five Years into the Central Bank of Chile's Independence Conference for useful comments, and Eun Sung Jang, Anne Lalramnghakhleli Moses, and Chifundo Moya for excellent research assistance. Any errors are our responsibility. The views expressed herein are those of the authors and do not necessarily reflect the views of the National Bureau of Economic Research.

NBER working papers are circulated for discussion and comment purposes. They have not been peerreviewed or been subject to the review by the NBER Board of Directors that accompanies official NBER publications.

(C) 2015 by Olivier Blanchard, Jonathan D. Ostry, Atish R. Ghosh, and Marcos Chamon. All rights reserved. Short sections of text, not to exceed two paragraphs, may be quoted without explicit permission provided that full credit, including $(\mathcal{C}$ notice, is given to the source. 
Are Capital Inflows Expansionary or Contractionary? Theory, Policy Implications, and Some Evidence

Olivier Blanchard, Jonathan D. Ostry, Atish R. Ghosh, and Marcos Chamon

NBER Working Paper No. 21619

October 2015

JEL No. F21,F23

\section{ABSTRACT}

The workhorse open-economy macro model suggests that capital inflows are contractionary because they appreciate the currency and reduce net exports. Emerging market policy makers however believe that inflows lead to credit booms and rising output, and the evidence appears to go their way. To reconcile theory and reality, we extend the set of assets included in the Mundell-Fleming model to include both bonds and non-bonds. At a given policy rate, inflows may decrease the rate on non-bonds, reducing the cost of financial intermediation, potentially offsetting the contractionary impact of appreciation. We explore the implications theoretically and empirically, and find support for the key predictions in the data.

Olivier Blanchard

Peterson Institute for International Economics

1750 Massachusetts Avenue, NW

Washington, DC 20036

and NBER

oblanchard@piie.com

Jonathan D. Ostry

Research Department

International Monetary Fund

HQ1-10-700

700 19th Street, N.W.

Washington DC, 20431

jostry@imf.org
Atish R. Ghosh

Research Department

International Monetary Fund

HQ1-09-612

700 19th Street, N.W.

Washington DC, 20431

aghosh@imf.org

Marcos Chamon

Research Department

International Monetary Fund

HQ1-09-612

700 19th Street, N.W.

Washington DC, 20431

mchamon@imf.org 


\section{INTRODUCTION}

Are capital inflows expansionary or contractionary? One would think that the question was settled long ago. But, in fact, it is not. And there is a striking schizophrenia:

Standard models, along Mundell Fleming lines ${ }^{1}$ or more modern incarnations, give one answer: For a given monetary policy rate, inflows lead to an appreciation, and thus a contraction in net exports and, in turn, a contraction in output. Only if the policy rate is decreased sufficiently, can capital inflows be expansionary. ${ }^{2}$

Emerging market policy makers however have a completely different view. They see capital flows as leading to credit booms and an increase in output, which can only be offset by an increase in the policy rate. They point to a policy dilemma: while the direct effect of an increase in the rate is to limit the increase in output, it may lead to even higher capital inflows, and this second effect may dominate the first. ${ }^{3}$

The evidence appears to support the beliefs of policy makers: Capital inflows appear to be typically associated with appreciations, credit booms, and an increase in output. They also appear to play a major role in driving boom-bust cycles (Reinhart and Reinhart 2009).

How can we reconcile the models and reality? The answer we offer in this paper is a simple one: By extending the set of assets in the economy, by allowing for both bonds (the rate on which can be thought of as the policy rate) and "non-bonds," i.e., other assets such as stocks, bank deposits, etc, and with both assets being imperfect substitutes. In this case, even if the policy rate - which we take to be the rate on bonds - is given, inflows may decrease the rate on non-bonds, in effect decrease the cost of financial intermediation. The positive effect of these lower rates on domestic demand may then offset the adverse effects of the appreciation on external demand. Capital inflows need not, but may, be expansionary even for a given policy rate.

This is the model we develop in this paper. It has a number of important implications:

The first is that the macroeconomic effects of capital inflows on output depend very much on their nature. For a given policy rate, bond inflows lead only to an exchange rate appreciation and

\footnotetext{
${ }^{1}$ Mundell (1963), Fleming (1962), Dornbusch (1976)

${ }^{2}$ Symmetrically, using such a model, Paul Krugman argues in his 2013 Mundell Fleming lecture that capital outflows are expansionary.

${ }^{3}$ Recourse to heterodox instruments, such as capital controls, are invoked to overcome this dilemma. See Ostry et al. (2012) for empirical evidence on the effectiveness of these measures during the global financial crisis. Existing empirical evidence suggests a positive correlation between domestic interest rates and inflows to EMEs, though the estimated correlations are not always significant and certainly weaker than the evidence for the effects on EME flows of low interest rates in advanced economies: Ghosh et al. (2014).
} 
are contractionary. In contrast, "non-bond" inflows lead to both an appreciation and a decrease in their rate of return; depending on which effect dominates, such flows may be expansionary. The second, which follows, is that appropriate policies vis-à-vis capital inflows depend very much on the nature of inflows:

Sterilized foreign exchange (FX) intervention, if done through bonds (as is usually the case), can fully offset the effects of bond inflows, leaving both the exchange rate and interest rates unchanged. In effect, the central bank takes the opposite position of foreigners: As foreigners decrease their holdings of foreign assets and increase their demand for domestic bonds, the central bank decreases its demand for domestic bonds and increases its holdings of foreign assets. When, however, sterilized foreign exchange intervention is used in response to non-bond inflows, it can avoid the exchange rate appreciation, but this comes with a larger decrease in the rate of return on non-bonds.

A similar distinction applies to capital controls. To the extent that capital controls are mainly targeted at bond inflows, non-bond inflows will dominate and lead to a currency appreciation and a decrease in the rate of return on non-bonds. To the extent that capital controls are mainly targeted at non-bond inflows, bond inflows will dominate, leading to an appreciation, no change in interest rates, and thus a decrease in output.

What is then the right mix of FX intervention, capital controls, and policy rate changes? This depends very much on whether lower interest rates on non-bonds - or, in a more general interpretation of our model, higher credit growth — is good or bad i.e., whether it leads to excessive credit and a bust following the initial boom. As we do not formalize distortions, be they real (e.g., Dutch disease) or financial, our model is not equipped to answer this question, but suggests the following conclusion:

If the country wants to increase output, and has macro prudential tools to avoid excessive credit growth, then non-bond flows are more attractive than bond flows: While both lead to an appreciation, non-bond flows decrease the rate of return on non-bonds, while bond flows do not, and lead to more of an appreciation. Tools that target one type of inflow, such as sterilized intervention in response to bond flows and not to non-bond flows, or capital controls that differentiate between bond and non-bond flows, are thus preferable to tools that do not, such as the policy rate.

The paper is organized as follows:

Section 1 presents a simple version of the model.

Section 2 extends the model to look at the role of sterilized FX intervention, and of capital controls.

Section 3 looks at the empirical evidence in the light of the model. It confirms its main prediction, namely a stronger effect of non-bond flows than bond flows on output. We find the effect of 
exogenous movements in bond flows on output to be negative but insignificant, whereas the effects of exogenous movements in non-bond flows are positive and significant.

\section{A Portfolio Model}

For the reasons we gave in the introduction, to answer the question at hand, a model of capital flows must have, in addition to money (so the central bank can set the policy rate), at least:

(1) Two domestic assets, call them domestic bonds and domestic "non-bonds"; these two assets must be imperfect substitutes, so capital inflows can potentially affect the rate on non-bonds given the rate on bonds. We think of "bonds" as the assets whose rate of return is directly controlled by monetary policy and the assets that are close substitutes for it. We think of "non-bonds" as all other assets, whose rate of return relative to bonds can be significantly affected by capital inflows. These include in particular foreign direct investment, domestic equities, and domestic bank liabilities.

(2) One foreign asset, call it foreign bonds; this asset must be an imperfect substitute for both domestic bonds and domestic non-bonds, so that differences in rates of return between domestic assets and foreign bonds do not lead to infinite capital flows.

\subsection{The Demand for Assets}

Let $M_{D}, B_{D}, N_{D}$ and $B_{D}^{*}$ denote the demand by domestic investors for domestic money, domestic bonds, domestic non-bonds, and foreign bonds respectively, where the subscript $D$ denotes asset demands by domestic residents. Let $R_{B}, R_{N}$ be the rates of return on domestic bonds and non-bonds respectively. Let $R^{*}$ be the rate of return on foreign bonds in foreign currency. Let $E$ be the exchange rate (defined so an increase in $E$ is an appreciation of the domestic currency) and let $E_{+1}^{e}$ denote the expected exchange rate next period, so $R^{*} E / E_{+1}^{e}$ is the rate of return on foreign bonds in domestic currency. Let $W$ be domestic wealth.

We assume that the demand for money by domestic investors is given by:

$$
M_{D}=\left(\alpha_{0}-\alpha_{1} R_{B}\right)
$$

Money demand is assumed to depend only on the interest rate on bonds, which we think of as the policy rate ${ }^{4}$.

\footnotetext{
${ }^{4}$ This is a conventional assumption, but one that has a relevant implication later when we introduce sterilized FX intervention. Sterilized FX intervention can be defined either as an intervention which leaves the policy rate unchanged, or an intervention which leaves the money stock unchanged. In general, if money demand depends not only on the policy rate but also on the other rates of return, the two will not be the same. With this specification, they are.
} 
The demands by domestic investors for the three other assets are given by: ${ }^{5}$

$$
\begin{aligned}
B_{D} & =\left(a+\beta\left(R_{B}-R_{N}\right)+\beta\left(R_{B}-R^{*} E / E_{+1}^{e}\right)\right)\left(W-M_{D}\right) \\
N_{D} & =\left(b+\beta\left(R_{N}-R_{B}\right)+\beta\left(R_{N}-R^{*} E / E_{+1}^{e}\right)\right)\left(W-M_{D}\right) \\
B_{D}^{*} / E & =\left(c+\beta\left(R^{*} E / E_{+1}^{e}-R_{B}\right)+\beta\left(R^{*} E / E_{+1}^{e}-R_{N}\right)\right)\left(W-M_{D}\right)
\end{aligned}
$$

To satisfy the budget constraint the constants must satisfy $a+b+c=1$. The demand for each asset is proportional to wealth net of money demand. And it depends on the rate of return on the asset relative to the rate of return on the other two assets. An equal increase in all rates of return leaves demands unchanged. The assumption that all coefficients are equal (to $\beta$ ) is easily relaxed (so long as the coefficients satisfy the adding up constraint that the sum of asset demands is equal to domestic wealth) to allow, for example, for different degrees of substitutability between domestic assets, and between domestic and foreign assets. But, for our purposes, this extension is inessential, and the assumption makes the algebra much simpler.

Initial domestic holdings are given by $\bar{M}_{D}, \bar{B}_{D}, \bar{N}_{D}, \bar{B}_{D}^{*}$ and wealth is given by:

$\bar{W}=\bar{M}_{D}+\bar{B}_{D}+\bar{N}_{D}+\bar{B}_{D}^{*}$

Turning to foreign investors, we assume that they do not want to hold domestic money, and have the choice between foreign bonds and either domestic bonds or domestic non-bonds. We specify their demands for domestic bonds and non-bonds (their demands for foreign money and foreign bonds play no role in determining equilibrium, so we do not need to specify them) as:

$$
\begin{gathered}
B_{F}=\left(d+\beta\left(R_{B}-R_{N}\right)+\beta\left(R_{B}-R^{*} E / E_{+1}^{e}+s_{B}\right)\right)\left(W^{*}-M_{D}^{*}\right) \\
N_{F}=\left(f+\beta\left(R_{N}-R_{B}\right)+\beta\left(R_{N}-R^{*} E / E_{+1}^{e}+s_{N}\right)\right)\left(W^{*}-M_{D}^{*}\right)
\end{gathered}
$$

The demand functions depend on foreign wealth net of demand for foreign money, and on relative rates of return of domestic bonds and non-bonds versus foreign bonds. The coefficients on relative returns are assumed equal for simplicity, and equal to those for domestic investors. The difference between foreign and domestic investors is captured by $s_{B}$ and $s_{N}$, shifts in the foreign demand for domestic bonds and domestic non-bonds respectively, and the source of capital flows in the model. Our interest is precisely in the effect of $s_{B}$ and $s_{N}$ on the equilibrium exchange rate and the equilibrium rates of return.

\footnotetext{
${ }^{5}$ Our assumption that capital flows respond to a return differential but at a finite pace is rooted in vintage open economy models with imperfect asset substitutability (e.g. Kouri 1976). Indeed, our portfolio model draws and Branson, Halttunen, and Mason (1977), and Friedman (1978). While plausible, the demand functions are not derived from optimization. The justification is the usual one, simplicity of the resulting equations and solutions. (A recent paper by Gabaix and Maggiori (2015) presents however a micro-founded model where capital flows are channeled by financial intermediaries that must be compensated by the risk they hold when there are imbalances in the demand for financial assets, which generates similar demand functions to the ones assumed in this paper.)
} 
Initial foreign holdings are given by $\bar{B}_{F}$ and $\bar{N}_{F}$.

Finally, the central bank is assumed to issue money against domestic bonds (we leave the possibility of buying foreign bonds to later). Thus, it chooses the money supply, $M$, and its holdings of domestic bonds $B_{C B}$, with $M-B_{C B}=\bar{M}-\bar{B}_{C B}$.

\subsection{Equilibrium Conditions}

Equilibrium requires that domestic asset markets clear, and that the capital account balances ${ }^{6}$ :

$$
\begin{aligned}
M & =M_{D} \\
\bar{B}_{D}+\bar{B}_{F}+\bar{B}_{C} & =B_{D}+B_{F}+B_{C B} \\
\bar{N}_{D}+\bar{N}_{F} & =N_{D}+N_{F} \\
\left(B_{F}-\bar{B}_{F}\right)+\left(N_{F}-\bar{N}_{F}\right) & =\left(B_{D}^{*}-\bar{B}_{D}^{*}\right) / E
\end{aligned}
$$

By Walras law, we can drop one of the conditions. And the assumption that monetary policy sets the policy rate at some value $R_{B}$ allows us to drop one other equation. (Note that given the specification of money demand as depending only on the rate on bonds, the central bank can keep $R_{B}$ constant just by keeping $M$ constant. In other words, it does not need to engage in open market operations in response to inflows.) We keep the equation for non-bonds and the capital account balance condition, which together determine $R_{N}$ and $E / E_{+1}^{e}$.

Without loss of generality, we take $E_{+1}^{e}$ to be equal to one. For notational convenience, we also take the two (gross) rates of return on domestic bonds, $R_{B}$, and foreign bonds, $R^{*}$, to be equal, and both equal to one (except when we look at changes in the policy rate later on). And we assume that wealth net of money demand is the same in both countries, eliminating (unimportant) relative size effects, and simplifying notation.

With these assumptions, the equilibrium condition for non-bonds becomes:

$$
\left[\left(R_{N}-1\right)+\left(R_{N}-E\right)\right]+\left[\left(R_{N}-1\right)+\left(R_{N}-E+s_{N}\right)\right]=0
$$

Where the first term in brackets corresponds to domestic demand for domestic non-bonds, and the second term to foreign demand for domestic non-bonds. For given supply, an increase in

\footnotetext{
${ }^{6}$ Note that, in specifying the capital account equilibrium condition, we ignore movements in the current account. Implicitly, we assume that the period we are looking at is short enough that we can ignore induced changes in the current account balance. A fully dynamic model would allow the current account to adjust over time. It would not however change the basic conclusions of the paper.
} 
domestic demand must be offset by a decrease in foreign demand, and vice-versa. The capital account balance condition becomes:

$$
\left[\left(1-R_{N}\right)+\left(1-E+s_{B}\right]+\left[\left(R_{N}-1\right)+\left(R_{N}-E+s_{N}\right)\right]=(E-1)+\left(E-R_{N}\right)\right.
$$

Where the two terms in brackets on the left correspond to the foreign demands for domestic bonds and non-bonds, and the term on the right corresponds to the domestic demand for foreign bonds. Absent FX intervention, an increase in the foreign demand for both domestic assets must be offset by an increase in the domestic demand for foreign assets.

Solving for $R_{N}$ and $E$ gives:

$$
\begin{aligned}
& R_{N}=1+\frac{1}{6} s_{B}-\frac{1}{6} s_{N} \\
& E=1+\frac{1}{3} s_{B}+\frac{1}{6} s_{N}
\end{aligned}
$$

Inflows are in turn given by:

$$
B_{F}-\bar{B}_{F}+N_{F}-\bar{N}_{F}=\frac{1}{2} \beta s_{B}+\frac{1}{2} \beta s_{N}
$$

These three equations contain the two main implications of the model. For a given policy rate:

- An increase in bond inflows leads to an appreciation and an increase in the rate on non-bonds. Since, by assumption, the central bank sets the policy rate, the increased demand for domestic bonds has no effect on the policy rate. The inflow, however, leads to an appreciation, and thus an expected depreciation, which makes holding domestic non-bonds less attractive to foreigners. This in turn increases the equilibrium rate of return on non-bonds. Both the appreciation and the higher rate on non-bonds are likely to be contractionary.

- An increase in non-bond inflows leads to an appreciation and to a decrease in the rate on non-bonds. The inflow leads to an appreciation, and thus to an expected depreciation, thus dampening the demand for domestic assets. But the demand for domestic non-bonds still increases, leading to a decrease in the rate on non-bonds. Thus, depending on the net effect of the appreciation and the lower rate, non-bond inflows may be contractionary (but less so than bond inflows) or expansionary. In emerging markets, with a relatively primitive financial system, the decrease in the rate may dominate, leading to a credit boom and an output increase, despite the appreciation. In more advanced economies, the appreciation may 
dominate; this may for example be the case for Switzerland, which in the recent past, has clearly perceived large capital inflows as contractionary.

Our model thus offers a tentative reconciliation between the Mundell Fleming and the policy makers' views. Whether inflows are contractionary or expansionary depends on their nature. Bond flows, at a given policy rate, are contractionary. Non-bond flows, at a given policy rate, may be expansionary, depending on the strength of their effect on the exchange rate and on the financial system. They are more likely to be expansionary in primitive financial systems, more likely to be contractionary in more advanced financial systems. This analysis suggests a simple way of looking at data, separating between bond and non-bond flows. Before we do so, we turn to the role of sterilized FX intervention and capital controls in the model.

\section{FX Intervention, Capital Controls, and the Policy Rate}

We proceed in two steps, first describing the different effects of FX intervention, capital controls, and the policy rate on the exchange rate and the rates of return on bonds and non-bonds, then drawing some tentative normative implications.

\subsection{Sterilized Intervention}

To allow for sterilized intervention, we now allow the central bank not only to buy and sell domestic bonds (as we have assumed until now, although it did not do any buying or selling in the equilibrium described above), but also to buy and sell foreign bonds. Thus, in response to a capital inflow, be it an increase in the demand for domestic bonds or non-bonds, it can intervene, i.e., increase its purchases of foreign bonds. It can then sterilize the intervention, in terms of its effects on the money stock (and, given our assumptions, also in terms of its effects on the rate of interest on domestic bonds), by selling an equivalent amount of domestic bonds. ${ }^{7}$

Let $M, B_{C B}, B_{C B}^{*}$ represent money, central bank holdings of domestic and foreign bonds

respectively. Then $M-B_{C B}-B_{C B}^{*}=\bar{M}-\bar{B}_{C} B-\bar{B}_{C B}^{*}$. Let, for notational convenience $X \equiv\left(B_{C B}^{*}-\bar{B}_{C B}^{*}\right) / \beta$ be the size of the sterilized intervention, normalized by $\beta$. The two equations characterizing equilibrium are the equilibrium condition for non-bonds, which is unchanged,

$$
\left[\left(R_{N}-1\right)+\left(R_{N}-E\right)\right]+\left[\left(R_{N}-1\right)+\left(R_{N}-E+s_{N}\right)\right]=0
$$

and the capital account equilibrium condition, modified to reflect the purchases of foreign bonds by the central bank, captured by X:

\footnotetext{
${ }^{7}$ One could allow for sterilization to take the form of purchases or sales of domestic non-bonds. But this is typically not what central banks do when they sterilize, and does not yield particular insights.
} 


$$
\left[\left(1-R_{N}\right)+\left(1-E+s_{B}\right)\right]+\left[\left(R_{N}-1\right)+\left(R_{N}-E+s_{N}\right)\right]=(E-1)+\left(E-R_{N}\right)+X
$$

Solving these two equations yields:

$$
\begin{aligned}
& R_{N}=1+\frac{1}{6} s_{B}-\frac{1}{6} s_{N}-\frac{1}{6} X \\
& E=1+\frac{1}{3} s_{B}+\frac{1}{6} s_{N}-\frac{1}{3} X
\end{aligned}
$$

Capital inflows are in turn given by the sum of bond and non-bond inflows:

$$
B_{F}-\bar{B}_{F}+N_{F}-\bar{N}_{F}=\frac{\beta}{2}\left(s_{B}+s_{N}+X\right)
$$

Now suppose that the central bank uses sterilized intervention to maintain a constant exchange rate in the face of inflows.

To leave the exchange rate constant in the face of bond inflows $\left(s_{B}>0, s_{N}=0\right)$, the central bank must choose $X=s_{B}$. This implies $E=1$ by assumption and implies $R_{N}=1$. Thus, (full) sterilized intervention cancels the effects of bond inflows on both the exchange rate and the rate on non-bonds. All that happens in this case is a change of ownership of domestic bonds. The foreigners hold more domestic bonds, the central bank holds fewer domestic bonds.

To leave the exchange rate constant in the face of non-bond inflows ( $\left.s_{B}=0, s_{N}>0\right)$, the central bank must choose $X=1 / 2 s_{N}$. This implies $E=1$ by assumption and implies $R_{N}=1-1 / 4 s_{N}$.

Note that the decrease in $R_{N}$ is larger than it would be absent FX intervention. The reason is that, by preventing appreciation, the central bank makes it more appealing for foreigners to buy domestic non-bonds, leading to a larger decline in their rate. Note that, indeed, inflows are larger under sterilized intervention.

These two results point to the main characteristics of FX intervention as a capital flow management in the face of inflows: FX intervention limits the appreciation, but it increases inflows, and thus increases the effects of inflows on the financial system. ${ }^{8}$

\footnotetext{
${ }^{8}$ Ostry, Ghosh and Chamon (2012) discuss further the role of foreign exchange market intervention as a tool for managing the exchange rate in the face of capital inflows.
} 


\subsection{Capital Controls}

Capital controls can be aimed at bond flows, at non-bond flows, or at both. ${ }^{9}$ Trivially, if successful, they can reduce or even eliminate all capital inflows, eliminating the effects of $s_{B}$ and $s_{N}$ on both the exchange rate and the rate on non-bonds (in contrast to FX intervention that reduces the first, but amplifies the second). Of more interest here is to look at the effects of capital controls aimed primarily at bonds or primarily at non-bonds.

Suppose, first, that capital controls fully eliminate the purchases of domestic bonds by foreigners. So by assumption the foreign demand for domestic bonds, $B_{F}$, is equal to zero, and the foreign demand for domestic non-bonds is given by:

$$
N_{F}=\left(f+\beta\left(R_{N}-E+s_{N}\right)\right)\left(W^{*}-M_{D}^{*}\right)
$$

As foreigners only have the choice between foreign bonds and domestic non-bonds, the capital account balance condition is in turn given by:

$$
\left(R_{N}-E+s_{N}\right)=(E-1)+\left(E-R_{N}\right)
$$

Solving for the rate of return on non-bonds and the exchange rate gives:

$$
\begin{gathered}
R_{N}=1-\frac{1}{5} s_{N} \\
E=1+\frac{1}{5} s_{N}
\end{gathered}
$$

As intended, capital controls obviously eliminate the effects of bond flows on both the exchange rate and the rate on non-bonds. But, relative to no capital controls, they increase the effects of non-bonds flows on both the exchange rate and the rate on non-bonds.

The reason is the following: Absent capital controls, non-bond flows lead to appreciation, which in turn leads to a decrease in bond flows, which in turn dampens the appreciation. Absent bond flows, this dampening effect is not there, and the appreciation is larger.

Suppose instead that capital controls fully eliminate the purchases of domestic non-bonds by foreigners, so $R_{N}$ is determined only by domestic demand, and is unaffected by $s_{N}$. Following the same steps as above, the exchange rate is given by:

\footnotetext{
${ }^{9}$ There has been a clear evolution of views regarding the use capital controls, moving from the notion that they should typically be avoided to the notion that, together with other instruments, they can be appropriate tools to respond to capital inflows, e.g. Ostry et al. (2010), Ostry et al. (2011) and IMF (2012).
} 


$$
E=1+\frac{2}{3} s_{B}
$$

Thus, controls on non-bond inflows magnify the effect of bond inflows on the exchange rate (relative to the case of no controls). The reason is the same as before. Absent controls, the appreciation would lead to a decrease in non-bond inflows. Absent non-bond inflows, this dampening effect is not present, leading to a larger appreciation.

To summarize, capital controls can, at least in theory, isolate the economy from capital flows altogether. Targeted capital controls affect the mix of flows, and thus the effects on the exchange rate and the financial system. Capital controls on bond flows for example will, by assumption, eliminate the effects of (incipient) bond flows, but will increase the effects of non-bond flows, both on the exchange rate and on the rate of return on non-bonds.

\subsection{Policy Rate}

Until now, we have assumed the policy rate $R_{B}$ to be equal to $R^{*}$, itself equal to 1 . We now reintroduce $R_{B}$ and consider its effects. Solving the equilibrium equations gives: ${ }^{10}$

$$
\begin{aligned}
& R_{N}=R_{B}+\frac{1}{6} s_{B}-\frac{1}{6} s_{N} \\
& E=R_{B}+\frac{1}{3} s_{B}+\frac{1}{6} s_{N}
\end{aligned}
$$

And the inflows are given by:

$$
B_{F}-\bar{B}_{F}+N_{F}-\bar{N}_{F}=\frac{\beta}{2}\left(s_{B}+s_{N}\right)
$$

Note that, in equilibrium, the inflows do not depend on $R_{B}$ : this is because an increase in $R_{B}$ leads simultaneously to an increase in $R_{N}$, making both domestic bonds and domestic non-bonds more attractive, and an increase in the exchange rate, making both less attractive, with a zero net effect on flows.

Suppose that, in the presence of non-bond flows, the central bank wants to keep the exchange rate constant through the use of the policy rate. It must decrease the policy rate $R_{B}$, so $R_{B}=1-1 / 6 s_{N}$. The exchange rate remains constant, and $R_{N}=1-1 / 3 s_{N}$.

\footnotetext{
${ }^{10}$ A minor cheat: a change in $R_{B}$ changes the demand for money and thus requires a change in the money supply.

This in turn leads to a change in wealth net of money demand $W-M_{D}$, and thus to a change in the demand for other assets for given rates of return. Given that money holdings are a small proportion of total wealth, we ignore this effect in the derivation below.
} 
Suppose that it wants instead to keep the rate of return on non-bonds constant. It must then increase the policy rate, $R_{B}$, so $R_{B}=1+1 / 6 s_{N}$. The rate on non-bonds remains constant, and the exchange rate increases to equal $E=1+1 / 3 s_{N}$.

This is the form the "policy dilemma" takes in our framework; whether to stabilize the exchange rate and accept a larger decline in the rate on non-bonds, or stabilize the rate on non-bonds and accept a larger appreciation. Note that, in both cases, in equilibrium, inflows are unaffected. In the first case, from the point of view of investors, the decrease in the policy rate is offset by a smaller expected depreciation (namely zero). In the second, the increase in the policy rate is offset by a larger expected depreciation.

How does the use of the decrease in the policy rate compare to the use of FX intervention in response to non-bond flows? Both lead to less appreciation and a further decline in the rate on non-bonds. But, if the two policies are used to keep the exchange rate constant, the decline in the rate of return on non-bonds is larger when the policy rate is used, $(-1 / 3)$ compared to $(-1 / 4)$ under FX intervention.

\subsection{Some Remarks on the Choice of Instruments}

The model we have developed is far short of what is needed to derive the optimal choice of instruments. Whether or not, and how, the central bank should use these instruments depends on the nature of underlying distortions in the economy:

If we think of the decrease in the rate on non-bonds as associated with credit growth, research has emphasized that while some additional credit growth, reflecting deepening of financial intermediation, may be desirable, "excessive credit growth" may be undesirable, raising the risk of a subsequent financial crisis. Thus, in terms of our model, the central bank may want to limit the decrease in $R_{N}$ in response to non-bond inflows.

The literature has also emphasized that while an appreciation increases real income, it also comes with the risk of "Dutch disease", the risk that excessive appreciation in response to capital inflows may lead to lasting damage to the tradable goods sector. ${ }^{11}$ Thus, the central bank may want to limit exchange rate appreciation.

Finally, traditional macro distortions such as nominal rigidities imply that, depending on their relative importance, the exchange rate appreciation and the decrease in the rate on non-bonds may - through their opposing effects on aggregate demand-lead to output above or below potential. This may again lead the central bank to want to use the above instruments.

\footnotetext{
${ }^{11}$ See, for example, Caballero and Lorenzoni (2014), Blanchard (2007), and Farhi and Werning (2012 and 2013).
} 
Assume that, for some of these reasons, the central bank cares about the degree of appreciation of the currency, or about the size of the decline of the rate on non-bonds, or both. How the instruments differ in response to increases in bond and non-bond flows is shown in Figures 1 and 2.

In Figure 1, the increase in bond inflows leads, absent policy responses, to a movement from point A to point $\mathrm{B}$. The exchange rate increases, and so does the rate on non-bonds. Both FX intervention and capital controls on bond inflows can reduce both effects and lead the economy along BA, potentially all the way back to point A. Using the policy rate also leads to a decrease, but along BD. Keeping the rate on non-bonds unchanged is associated with some exchange rate appreciation; keeping the exchange rate unchanged is associated with a decrease in the rate on non-bonds. Thus, if the purpose of the central bank is to avoid the appreciation without too much of a decline in the rate on non-bonds, FX intervention or capital controls seem preferable to the use of the policy rate.

In Figure 2, the increase in non-bond inflows leads, absent policy responses, to a movement from point $\mathrm{A}$ to point $\mathrm{B}$. The exchange rate increases, and the rate on non-bonds decreases. Capital controls lead to a movement along BA, potentially all the way back to A. FX intervention leads to a movement along BC. To keep the exchange rate unchanged using FX intervention, the central bank must accept some further decrease in $R_{N}$. A decrease in the policy rate leads to a movement along BD. To keep the exchange rate unchanged using the policy rate, the central bank must accept a larger decrease in $R_{N}$ than when it uses FX intervention. Thus, if the central bank wants to maintain exchange rate stability with minimum movement in $R_{N}$, capital controls are best, FX intervention is next best, and the use of the policy rate is last. If the central bank wants to keep the rate on non-bonds unchanged, then it has to move from $\mathrm{B}$ to $\mathrm{F}$, and accept a larger exchange rate appreciation. On the assumption that output depends negatively on $R_{N}$ and $E$, if the central bank wants to keep output constant using the policy rate, it has to choose a point between $\mathrm{D}$ and $\mathrm{F}$; this point may be to the right or to the left of $\mathrm{B}$, and thus require either a decrease or an increase in the policy rate.

Given the potentially many goals, and the fact that the instruments have different effects, the instruments can be combined in interesting ways. For example, the policy rate and FX intervention can be used to fully offset, if desired, the effects of inflows on both the exchange rate and the rate of return on non-bonds. 
Figure 1. Increase in bond inflows, $s \_B>0$

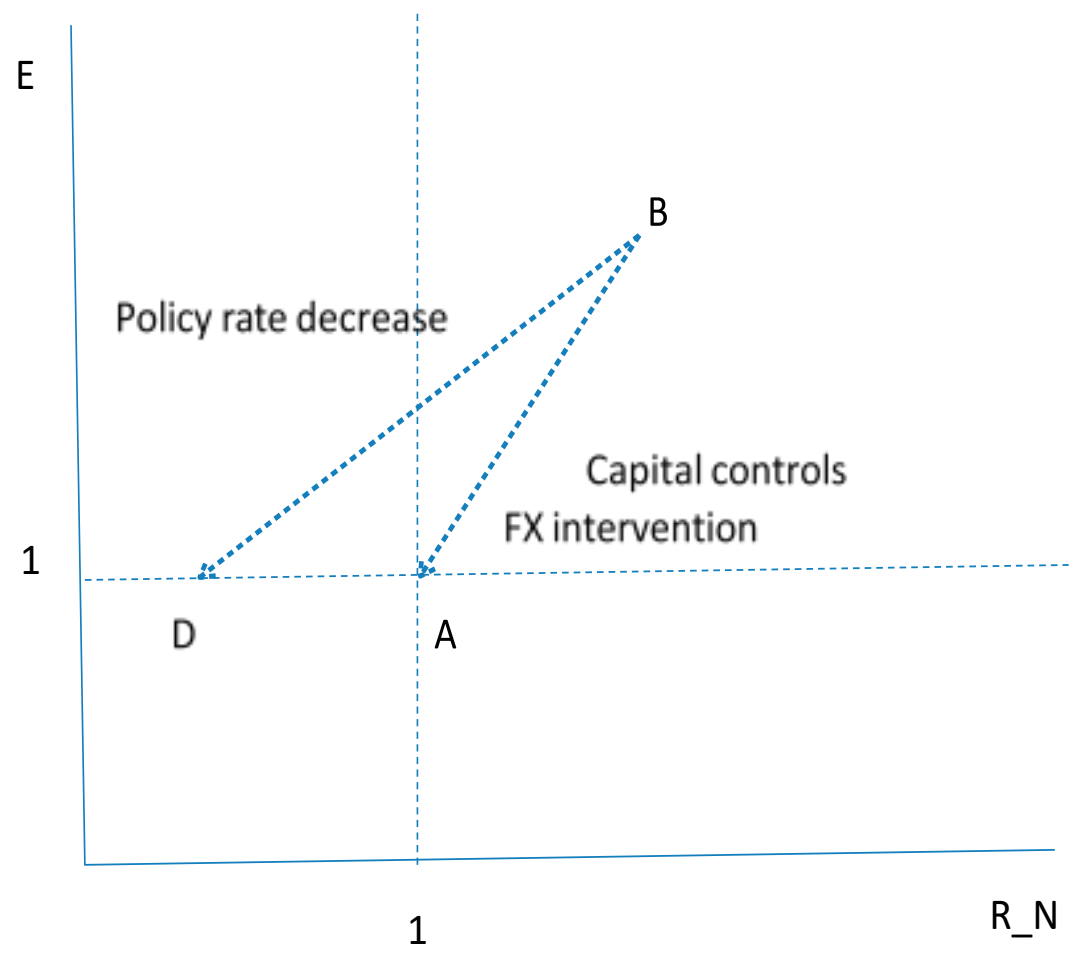

Figure 2. Increase in non-bond inflows, $s \_N>0$

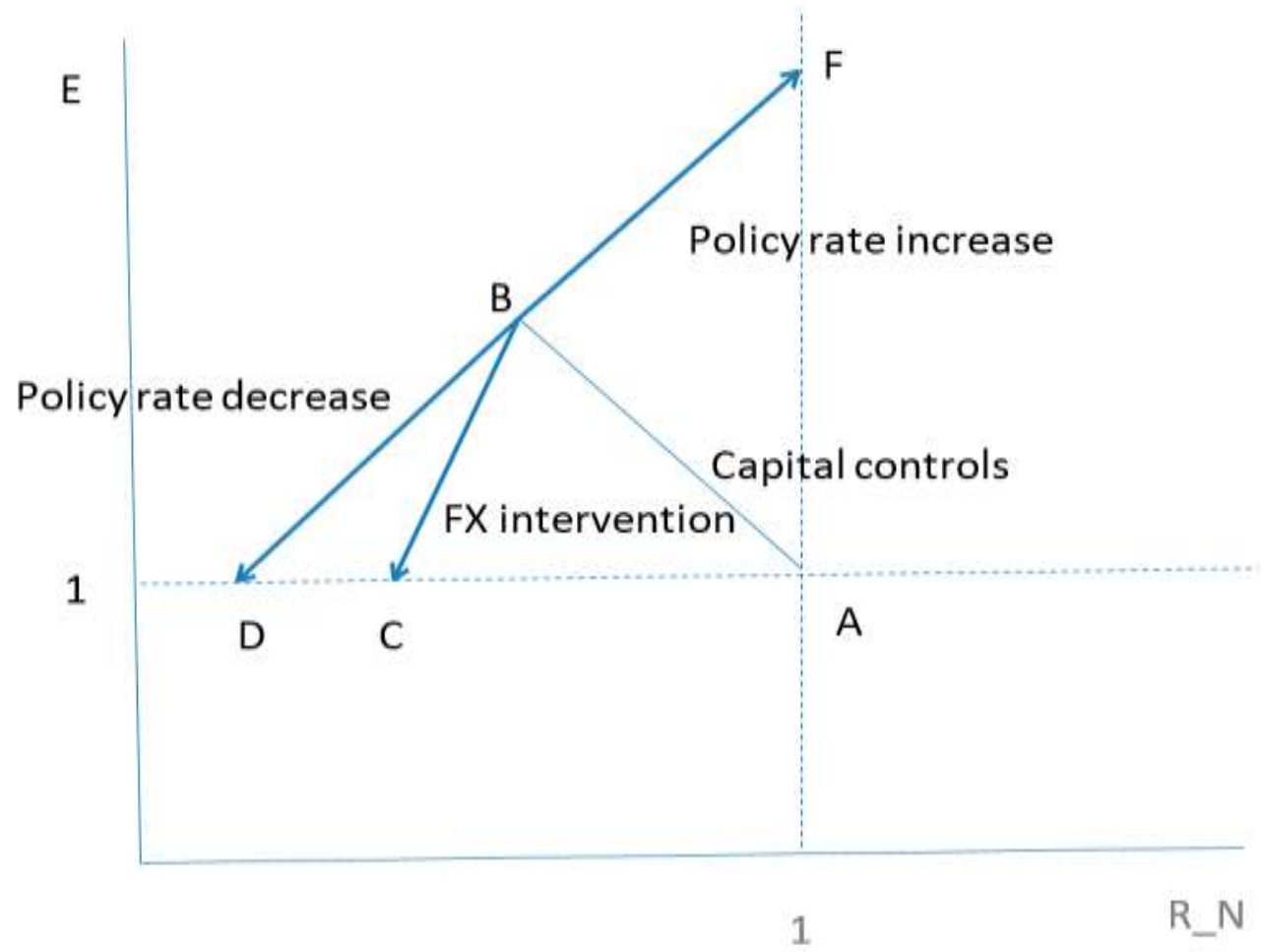


Using the equations above, the required policy rate and FX intervention are given by:

$$
R_{B}=1+\frac{1}{2} s_{N}
$$

and

$$
X=s_{B}+2 s_{N}
$$

Thus, in response to non-bond inflows, the central bank must increase the policy rate, while at the same time engaging in a large FX intervention. The increase in the policy rate is needed to leave the rate on non-bonds unchanged in the face of higher demand. But this increase, which makes domestic bonds more attractive, leads to larger inflows, and a potentially larger appreciation. Thus, these inflows must be offset by a larger FX intervention. ${ }^{12}$

The model we have developed here leaves out many relevant aspects of capital flows, capital controls and FX intervention. The persistence of flows clearly matters. So do the flexibility of capital control measures, the degree of substitution between assets which determine the size of the required FX interventions ( $\beta$ in our model). But, as simplistic as it is, it shows the importance of adapting policy responses to the type of inflows, and the different effects of the three sets of instruments in each case.

\section{SOME EMPIRICAL EVIDENCE}

In this section, we explore the central implication of our model, that non-bond flows, because they decrease the cost of credit for a given policy rate, are more likely than bond flows to lead to an increase rather than to decrease in output.

An empirical exploration faces at least two main challenges. The first one is that the previous argument applies to exogenous flows, i.e., not to flows triggered by developments in the country itself. The second is that, as we have seen in the previous section, aggressive use of the different policy instruments can cancel some of the effects of these flows and potentially reverse the results.

The first challenge requires the use of instruments, namely variables that affect the inflows but are plausibly not caused by events within the country. To do this, when looking at each country, we use global flows to all emerging market countries as instruments, on the assumption that these are unlikely to be correlated with developments in any particular emerging market country.

This gives us as many instruments as there are categories of flows, and allows us to estimate the effects of the different types of flows on domestic activity and credit. This is what we do first. We

\footnotetext{
${ }^{12}$ Thus, within the logic of the model, FX intervention and the policy rate can insulate the economy in the same way as capital controls (a more optimistic conclusion, at least on paper, than the proposition by Hélène Rey (2013) that, short of using macro prudential tools or capital controls, countries cannot divorce themselves from global financial flows). They have however different implications for output. A higher policy rate has a direct adverse effect on output, capital controls do not. Obviously many caveats apply, but the logical point remains and is important.
} 
find that, indeed, while bond flows have a negative effect on activity, non-bond flows have a significant and positive effect. We also find that non-bond flows, excluding FDI, have a strong positive effect on credit, much stronger than bond flows.

The specification does give us however the combined effects of the direct effects of flows and of whatever policies are followed by countries in response to these flows, be it the use of the policy rate or of FX intervention. To isolate the direct effects of flows, which is what our model makes predictions about, requires controlling for these policies as well. For the same endogeneity reason as for flows, these policies must also be instrumented, and additional instruments are required. Thus, in the second step, we extend the initial specification to allow for both the effects of flows and the effects of policies, and use the VIX and the US policy rate as additional instruments. These are, however, weaker instruments than aggregate flows, and thus the results must be seen as more tentative. They confirm nevertheless the results obtained in our first step. Controlling for the policy rate and for FX intervention, bond flows have a negative effect on activity, while non-bond flows have a positive and significant effect. And non-bond flows, excluding FDI, have a strong positive effect on bank credit to the economy, much stronger than bond flows.

We start by first estimating the effects of different flows on GDP growth. Our initial panel data specification is given by:

$$
X_{i t}=\beta_{1} B F_{i t}+\beta_{2} N B F_{i t}+\beta_{3} X_{i t}^{*}+\beta_{4} \Delta T O T_{i t}+\beta_{5} X_{i t-1}+D_{i}+D_{t}
$$

$X_{i t}$ is GDP growth in country $i$ in year $t, B F_{i t}$ is bond flows to country $i$ in year $t$, normalized by GDP in country $i$ in year $t, N B F_{i t}$ is non-bond flows to country $i$ in year $t$, normalized by GDP in country $i$ in year $t$. The next two variables control for other external developments, which may also affect domestic activity: $X_{i t}^{*}$ is partner growth for country $i$ in year $t$, and $\triangle T O T$ is the rate of change in the terms of trade for country $i$ in year $t . X_{i t-1}$ is lagged GDP growth. Finally, the specification allows for country and time dummies. The inflow variables are the liability flows and come from the IMF Financial Flows Analytics (FFA) database. We drop outliers where either flow variable is above the 99th percentile or below the 1st percentile in the sample, but our qualitative results are robust to whether these outliers are included or excluded. Further details on sources and construction of the variables here and below are given in the data appendix.

Our sample of countries consists of 19 major emerging market countries, Brazil, Chile, Colombia, the Czech Republic, Hungary, India, Indonesia, Israel, Korea, Malaysia, Mexico, Peru, the Philippines, Poland, Romania, Russia, Thailand, Turkey and South Africa. Our period of estimation is 2000 onwards, using annual data. 
While we control for two factors affecting GDP growth, namely partner GDP growth and the change in the terms of trade, the residual contains many more factors, and many of them can affect both GDP growth and inflows. For example, high domestic demand growth may lead to an increase in the policy rate which in turn increases primarily bond inflows; or, high productivity growth may lead both to high growth, and high portfolio equity or FDI inflows. The evidence on the "global financial cycle", i.e., the correlated flows to and from emerging market countries in response to changes in advanced country monetary policies or changes in market risk perceptions, suggests a natural set of instruments, namely global inflows to emerging market countries; these are unlikely to be correlated with developments in any particular emerging market country. This leads us to define two variables, global bond and non-bond inflows. For each country, global bond inflows are defined as the sum of inflows to all emerging market countries listed above leaving out the flows going to the country under consideration, divided by the sum of the GDPs of all emerging market countries listed above, again leaving out the GDP of the country under consideration. Global non-bond inflows (and other flow decompositions below) are constructed in a similar way. ${ }^{13}$

One issue, however, is that the effect of these global flows on flows to individual countries varies across countries; some countries are perceived as safe havens, others not. Thus, we interact these two global variables with country specific dummies, thus allowing their effects on the flows to vary across countries. Let $G B F_{i t}$ and $G N B F_{i t}$ be the global bond and non-bond flows constructed for each country. Our set of instruments is thus given by:

$$
D_{1} \mathrm{GBF}_{1, t}, \ldots, D_{19} \mathrm{GBF}_{19, t}, D_{1} \mathrm{GNBF}_{1, t}, \ldots, D_{19} \mathrm{GNBF}_{19, t}
$$

The results of estimation are given in column 1 of the table. The effect of bond flows is negative and insignificant, while the effect of non-bond flows is positive and significant, both statistically and economically: An increase in exogenous non-bond flows of 1 percent of GDP increases GDP growth by 0.31 percentage points. These results support our basic theoretical conclusion.

The data allow for further disaggregation. Thus, we decompose non-bond flows into FDI flows, portfolio equity flows, and "other flows". Each flow variable is constructed in the same way as before, and so are the corresponding instruments. The results are shown in column 2 . The effect of bond flows remains negative, and insignificant. The effects of each of the three other "non-bond" flows are positive, significant, and roughly of the same magnitude.

The argument we developed for why different types of flows had different effects is that non-bond flows decreased the non-bond rate relative to the policy rate, or more generally, reduced the costs of financial intermediation. We explored the effect of the flows on the spread between the lending rate and the policy rate. We found the effects to be insignificant, for both bond and

\footnotetext{
${ }^{13}$ This approach follows Blanchard et al (2015).
} 
non-bond flows. This is disappointing, but perhaps not surprising; the limitations of the lending rate as an indication of the cost of credit are well documented, as banks typically rely largely on non price rationing to limit credit. We also explored the effect of the different flows on the change in private credit normalized by GDP. The results are reported in column 3. The independent variables bond inflows, FDI flows, portfolio equity flows, and "other flows," partner growth, the change in terms of trade, the lagged dependent variable, and country and time dummies. The flows are instrumented in the same way as before. The effect of bond flows is positive, but insignificant. The effects of non-bond flows vary by type. FDI flows have a large negative and significant effect on credit: a plausible explanation is that some of the intermediation which would have taken place through banks is now replaced by FDI financing. Portfolio equity flows have a large positive, but statistically insignificant, effect on credit. "Other flows" have a positive, large and statistically significant effect on credit. An increase of 1 percent of GDP in "other flows" (of which bank flows account for about half on average) leads to a 0.6 percentage point increase in credit relative to GDP.

Our second step is to try to separate the direct effects of the flows from the policy responses induced by those flows. Column 4 extends the specification in Column 2 by adding two variables, FX intervention and the policy rate. The variable for FX intervention is constructed as reserve flows, normalized by GDP. Given the endogeneity of both policy measures, two additional sets of instruments are needed. We use the VIX and the 3-month US T-bill rate, both interacted with country dummies, as additional instruments. The coefficients on bond and non-bond flows are roughly similar to those in Column 2: The coefficient on bond flows is negative and insignificant. The coefficients on all three non-bond flows are positive, and significant. The policy rate has the expected sign. The coefficient on FX intervention, which our theory would predict to be positive, is small and insignificant.

Column 5 shows the effects of flows on the change in private credit. Again, the coefficients on bond and non-bond flows are largely similar to those of Column 3. Bond flows have a small, insignificant, effect on credit; FDI has a large, negative and significant, effect on credit; portfolio and other flows have a strong positive effect on credit. The coefficient on the policy rate is negative, but insignificant. One result is at odds with our model. Our theory implies that FX intervention should lead to less appreciation, a higher flow into non-bonds, and, more generally, more credit growth, but the coefficient on FX intervention is negative and significant. We have no ready interpretation of this result.

The set of regressions reported in the table is very much a first pass. Much more needs to be done to explore the effects of different flows on the financial system. But, overall, we see the set of results as strongly supportive of the distinction between bond and non-bond flows: Bond flows are contractionary. Non-bond flows can be expansionary. 
Table 1. Effect of Capital Flows on GDP and Credit Growth.

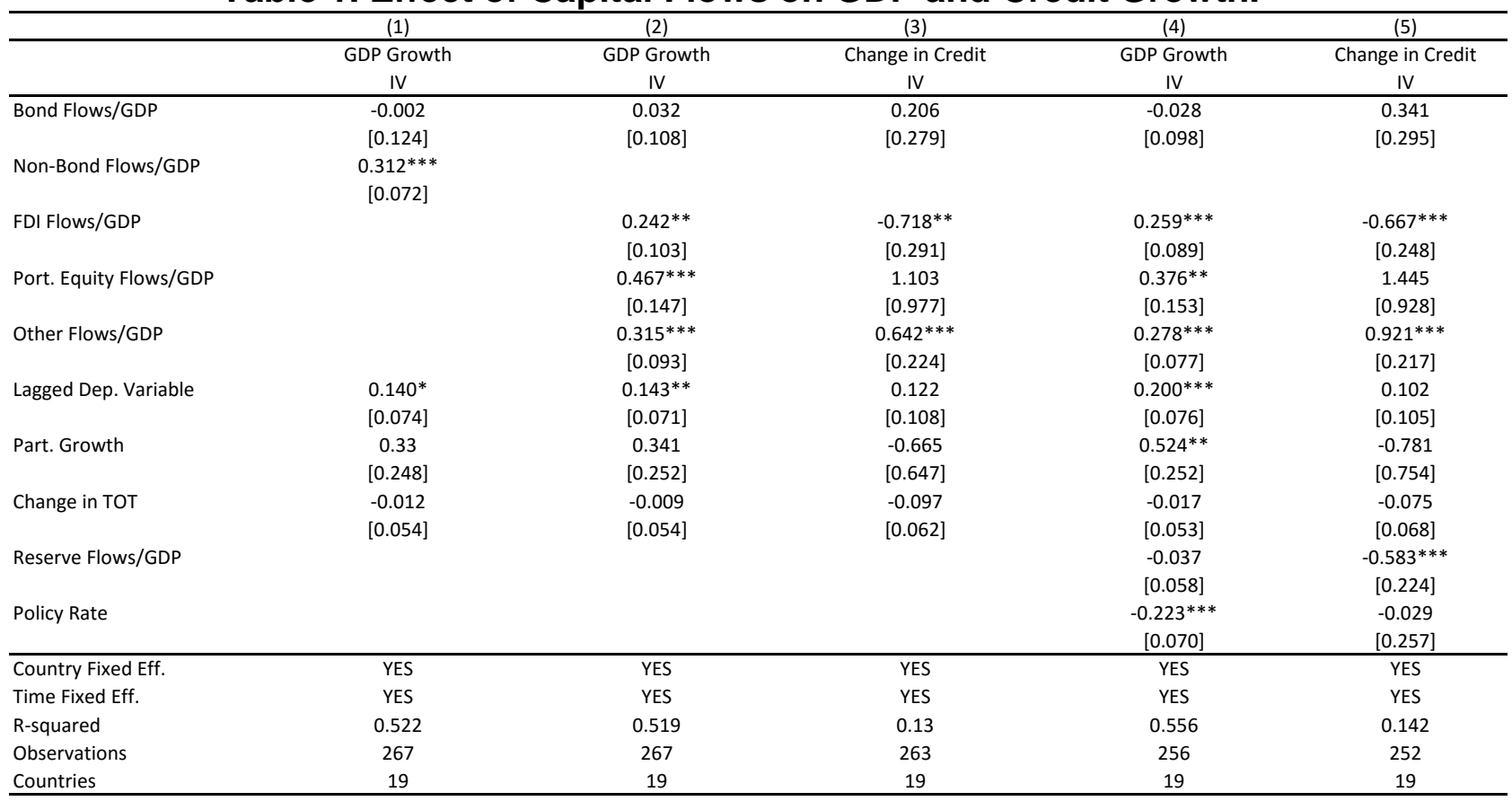

Notes: Each capital flow variable is instrumented by the interaction of country dummies with flow to the other countries in the sample in all specifications. In Columns 4 and 5 reserve flows and the policy rate are also instrumented, with the interaction of country dummies with the VIX and the US 3M T-bill rate being used as additional instruments. HAC standard errors in brackets. *, ** and $* * *$ denote statistical significance at the 10,5 and 1 percent level, respectively.

\section{Conclusions}

We started from the tension between theoretical model predictions about the effects of capital flows on output and policy makers' beliefs. We argued that whether capital inflows are expansionary or contractionary depends on their nature. For a given policy rate, bond inflows lead to an appreciation and are contractionary. For a given policy rate, non-bond inflows also lead to an appreciation, but they also decrease the cost of borrowing, and their net effect may be expansionary. The empirical evidence supports this basic conclusion: Exogenous bond flows appear to have on average small negative effects on output, while exogenous non-bond flows appear to have a positive effect. Our analysis, if correct, has important implications for the use of policy tools to deal with inflows. Different combinations of tools must be used depending on the nature of these inflows. 


\section{DAta APPENDix}

The source for the capital flow variables is the IMF Financial Flow Analytics (FFA) database, whose underlying data primarily draws upon the IMF Balance of Payment Statistics Database, BPM version 6.

Flows are measured in gross terms (net purchases or sales of domestic assets by foreign residents).

Bond Flows: Balance of Payments, Financial account, Portfolio investment, Debt securities.

Equity Flows: Balance of Payments, Financial account, Portfolio investment, Equity and investment fund shares.

FDI Flows: Balance of Payments, Financial account, Direct investment.

Other Flows: Balance of Payments, Financial account, Other investment, Non-official sector.

Non-Bond Flows: FDI Flows + Equity Flows + Other Flows (as defined above). ${ }^{14}$

Net Reserve Flows: Balance of Payments, Financial Account, Reserve Assets.

The capital flows are measured in current dollars and are scaled by the Nominal GDP in Dollars in that year.

Additional variables used: GDP Volume (from International Financial Statistics, IFS). Partner Growth: Real GDP (2005 constant local currency prices) of partner countries weighted by export shares (from World Economic Outlook, WEO). Terms of Trade (from WEO). Domestic Credit to the Private Sector (from World Development Indicators and IFS). Policy Interest Rate (from IFS). For countries where the policy interest rate (or equivalent) is not available we use the discount rate, and where that is not available the money market rate.

\footnotetext{
${ }^{14}$ Financial derivatives are not included in either the bond or the non-bond flow variables.
} 


\section{REFERENCES}

Blanchard, O., 2007, "Current Account Deficits in Rich Countries," IMF Staff Papers, vol. 54(2), pp. 191-219.

Blanchard, O., G. Adler, and I. de Carvalho Filho, 2015, “Can Foreign Exchange Intervention Stem Exchange Rate Pressures from Global Capital Flow Shocks?" NBER working paper 21427, July 2015.

Branson, W., H. Halttunen, and P. Masson, 1977, "Exchange Rates in the Short-Run: The Dollar-Deutschemark Rate” European Economic Review, Vol. 10, pp. 303-324.

Caballero, R. J., and G. Lorenzoni, 2014, "Persistent appreciations and overshooting: A normative analysis." IMF Economic Review, 62, pp. 1-47.

Dornbusch, R., 1976, "Expectations and Exchange Rate Dynamics" Journal of Political Economy, Vol. 84, No. 6, pp. 1161-1176.

Farhi, E., and I. Werning, 2012, "Dealing with the Trilemma: Optimal Capital Controls with Fixed Exchange Rates.” NBER Working Paper w18199.

Farhi, E. and I. Werning, 2013, “A Theory of Macroprudential Policies in the Presence of Nominal Rigidities.” NBER Working Paper w18199.

Fleming, J. M., 1962, "Domestic financial policies under fixed and floating exchange rates." IMF Staff Papers Vol. 9, pp. 369-379.

Friedman, B., 1978, “Crowding Out or Crowding In? The Economic Consequences of Financing Government Deficits.” Brookings Papers on Economic Activity, Vol. 3, pp. 593-654.

Gabaix, X., and M. Maggiori, 2015, "International Liquidity and Exchange Rate Dynamics," Quarterly Journal of Economics, 130 (3), pp. 1369-1420.

Ghosh, A. R., M. S. Qureshi, J. Kim, J. Zalduendo, 2014, “Surges” Journal of International Economics, 92, pp. 266-285.

International Monetary Fund, 2012, “The Liberalization and Management of Capital Flows: An Institutional View." Available at: http://www.imf.org/external/np/pp/eng/2012/111412.pdf.

Kouri, P., 1976. "Capital Flows and the Dynamics of the Exchange Rate.” Seminar Paper 67. Stockholm: Institute for International Economic Studies. 
Krugman, P., 2014, “Currency Regimes, Capital Flows, and Crises.” IMF Economic Review, forthcoming.

Mundell, R., 1963, "Capital mobility and stabilization policy under fixed and flexible exchange rates," Canadian Journal of Economics and Political Science, Vol. 29, pp. 475-85

Ostry, J. D., A. R. Ghosh, K. Habermeier, M. Chamon, M. S. Qureshi, and D. Reinhart, 2010, "Capital Inflows: The Role of Controls." IMF Staff Position Note No. 10/04.

Ostry, J. D., A. R. Ghosh, M. Chamon and M. S. Qureshi, 2011, "Capital Controls: When and Why?" IMF Economic Review 59, pp. 562-580.

Ostry, J. D., A. R. Ghosh, M. Chamon, and M. S. Qureshi, 2012, “Tools for managing financialstability risks from capital inflows." Journal of International Economics, 88(2), pp. 407-421.

Ostry, J. D., A. R. Ghosh, M. Chamon, 2012, “Two Targets, Two Instruments: Monetary and Exchange Rate Policies in Emerging Market Economies," IMF Staff Discussion Note No. $12 / 1$.

Reinhart, C. and V. Reinhart, 2009, "Capital Flow bonanzas: an encompassing view of the past and present." NBER Macroeconomics Annual, University of Chicago Press.

Rey, H., 2013, "Dilemma not Trilemma: The Global Financial Cycle and Monetary Policy Independence," Jackson Hole 2013. 